\title{
Exploration of Motives and Barriers on Indonesian Organic Products Consumption
}

\author{
Tony Wijaya ${ }^{1} \&$ Purwoko $^{2}$ \\ ${ }^{1}$ Faculty of Economic, Universitas Negeri Yogyakarta, Indonesia \\ ${ }^{2}$ Faculty of Economic and Business, Universitas Ahmad Dahlan, Indonesia \\ Correspondence: Tony Wijaya, Faculty of Economic, Universitas Negeri Yogyakarta, Indonesia. E-mail: \\ tony@uny.ac.id
}

$\begin{aligned} & \text { Received: May 31, } 2018 \quad \text { Accepted: August 1, } 2018 \quad \text { Online Published: August 11, } 2018 \\ & \text { doi:10.5539/gjhs.v10n9p66 } \quad \text { URL: https://doi.org/10.5539/gjhs.v10n9p66 }\end{aligned}$

\begin{abstract}
This study aims to explore consumer motives and barriers related to the consumption of organic products. The research was conducted using survey method. Respondents in this study are fixed consumers of organic products incorporated as members of the Indonesian Organic Community. Data is collected incrementally. Initial data were collected through an open survey, then Focus Group Discussion was conducted to classify the stimulus from consumers. The next data is collected in a closed and analyzed using Confirmatory Factor Analysis and descriptive. Based on the analysis indicates that the motives of consumers to consume organic based on the benefits of organic products is health, safety, naturalness, and the importance of maintaining environmental balance. External factors that determine the choice in the consumption of organic products is a life partner, family, friends or colleagues, while those used as a reference purchase is a media of information such as magazines and television in the form of talk shows and nutritionists. It is a barrier to consumption of organic products is the availability of sellers (ease in obtaining products), product prices, consumer income, knowledge and information of authenticity (validity) of organic products.
\end{abstract}

Keywords: motives, barriers, organic products, consumption

\section{Introduction}

Today organic products are believed to be healthier than conventional ones (Forman \& Silverstein, 2012; Mie et al., 2017; Suprapto \& Wijaya, 2012). Organic products, especially organic plants as containing less nitrate and pesticide residues, but more vitamins, as well as compounds that are beneficial to health than conventional ones (Rembialkowska \& Srednica, 2009). Organic products introduced in Indonesia tend to be slower than other countries such as Malaysia and other Asian countries (Suprapto \& Wijaya, 2012). Organic media in the UK reports that organic product sales in Asia are increasing by about $20 \%$ annually. Sales of organic vegetables in Beijing's supermarkets rose by $88 \%$ in the 12 months since November 2006. In addition to Asia, in some other countries like Uganda, most farmers have been certified organic and the country is recognized as Africa's largest producer of organic farming. Consumption of organic products in Indonesia is still relatively low, this is supported by data from YLKI (2012) survey results in 609 respondents in some regions in Indonesia which shows the low level of consumption in organic products. Based on the area of organic farming, in 2006 it was noted that there were 23,605 organic farmers with an area of organic farming of 41,431 Hectare or $0.09 \%$ of total agricultural land in Indonesia (International Federation of Organic Agriculture Movements, 2008). The total area of organic farming in Indonesia in 2011 decreased to 225,063 Hectare. This condition clearly shows the gap between the growing demand for organic products that continue to increase not in accordance with the area of production decline.

Some of the most sensitive issues in the organic product industry include nutritional attributes, food safety, and eco-labeling. The issue of safe food has increased public awareness of the environmental crisis that requires everyone to have a healthy and thrifty lifestyle (Junaedi, 2007) as well as the natural tendency (Chan, 2001). Understanding the factors that play a role in explaining the buying behavior of organic products is expected to reduce environmental degradation through the aspects of environmentally friendly consumption. Consumption of organic products can be used as a target for directing environmentally friendly behavior and improving the quality of life. The importance of understanding the behavior of consumption of organic products from the consumer side of the reasons for health, quality of life and the reasons for reducing environmental degradation (Tsakiridou et al., 2005). On the marketer's side, understanding the consumption of organic products is important as part of communication and marketing strategies for potential segments (Kalafatis et al., 1999) and useful for designing 
marketing strategies in achieving short- and long-term goals (Ham et al., 2016).

Several studies have examined the factors that contribute to the purchase of organic products in countries such as America, Canada, Europe and Costa Rica that are health, environment, chemical-free, environmental ethics, helping farmers (Calverley, 2005; Alberta Government, 2006). Aguirre (2007) in his research has identified several reasons that consumers consider buying organic products, namely the belief that organic products are healthy, protect the environment, relate to personal health, chemical-free and help farmers. Associated with the condition of organic products, the appearance or appearance, quality, freshness, availability, and price of the product are also part of consumer consideration in choosing organic products (Aguirre, 2007). Eco-oriented behavior is also shaped by the value that consumers believe is the natural human value orientation (Wijaya, 2017). The results of previous research findings vary widely depending on the conditions of different countries, both on the motives and barriers of consumption of organic products (Ruiz et al., 2018).

In addition to the motive for purchasing organic products, several studies also identify factors that constrain consumption of organic products in some countries such as price and availability (American, Canadian, European and Costa Rica countries), consumer awareness and (America), stability of distribution (Canada), and quality (Europe) (Calverley, 2005; Alberta Government, 2006). Ham et al. (2016) suggest there are some barriers for consumers to buy organic products that are negative attitude, cost, time, and knowledge. Buder et al. (2014) found that the reasons consumers do not buy organic products are price, availability and product quality. Studies on the consumption of organic products have been conducted in several developed countries such as Switzerland, Britain and several other developed Asian countries. Indonesia is a developing country that has different consumer characteristics, especially in attitude, culture, and value so it needs to be studied further. Other considerations, the prediction of a model may vary in different conditions and cultures (Bagozzi et al., 2000) such as consumer behavior (Hempel \& Jain, 2001). Such differences, in addition, will result in different empirical conditions also requiring different stimulus adjustments or different contexts in the measurement. This study was conducted in an effort to bridge the difference and explore more deeply about the motives and barriers of consumption of organic products in the context of Indonesia.

Organic products as environmentally friendly products are elements of an individual belief system (Dembkowski \& Lloyd, 1994). In a person's behavior is directed by the motives and beliefs in accordance with the culture. The motive for purchasing organic products is driven by concerns about environmental, health and taste issues. Consumers who purchase organic products can be classified as environmentally conscious consumers, phobias or fears of products containing chemical residues (ecological cognition and experience), supporting humanistic farming methods (ecological effects) and the belief that valuable products premiums are better and have more flavor and are able to pay (ecological effects and are willing to pay premium prices) (Davies et al, 1995).

In fact, the lack of availability of data and information relating to the environment and products that are claimed to be environmentally friendly causes consumers not to know the full truth of the claims of organic products. Consumers rely heavily on advertising, labeling, lightweight rubrics on popular media and word-of-mouth news. The market does not provide enough information for consumers to determine whether a product is organic or not, the product is only priced and unilateral advertisements from producers, so information from various parties such as from the government is indispensable for consumers to ensure organic products. Partially, some researches explore information related to the reasons for purchasing organic products, ie the value that consumers believe (Chan \& Lau, 2000; Fraj \& Martinez, 2006), consumer knowledge (Laroche et al., 2001; Magistris \& Gracia , 2008), attitudes of consumer evaluation (Aertsens et al., 2009; Lodorfos \& Dennis, 2008; Suprapto \& Wijaya 2012), references (Aertsens et al., 2009; Lodorfos \& Dennis, 2008; Sampson, 2009), other aspects of ease and barriers (Aertsens et al., 2009; Lodorfos \& Dennis, 2008; Tarkiainen \& Sundqvist, 2005). The reasons for purchasing organic products in some countries are health, environmental, chemical-free, environmental ethics, helping farmers (Calverley, 2005, Alberta Government, 2006). Other studies have identified the motive for purchasing organic products that believe that organic products are healthier than non-organic, protect the environment, relate to personal health, chemical or natural-free (Aguirre, 2007), help farmers (Aguirre, 2007) and tastes (Baudry et al., 2017). Based on the condition of organic products, the appearance or form, quality, freshness, availability, and price of the product are also part of consumer consideration in choosing organic products (Aguirre, 2007).

Barriers are part of the thing that controls the behavior of individuals. Ajzen (2005) explains that behavior can become apparent if the individual is able to control all the factors that play a role in whether or not to behave. Such factors can be internal such as competence, income, the time available to carry out behavior, and external factors such as the availability of tools or something required to perform such behavior. If the individual is unable to control the supporting factors or behavioral inhibitors then other factors alone are not sufficient to predict behavior. There are aspects of actual control that play a role in behavior like resources behave. The results of several studies 
on the factors that constrain the purchase of organic products have identified the factors that constrain consumers such as price and availability, consumer awareness, the stability of distribution, quality (Calverley, 2005, Alberta Government, 2006), and egoism (Doorn \& Verhoef, 2015). Research Ham et al. (2016) proves there are some barriers for consumers to buy organic products that are negative attitude, cost, time, and knowledge. Buder et al. (2014) found that the reason consumers do not buy organic products is the price, availability, and quality of the product, in contrast to the results of research Ruiz et al. (2018) found that the main barrier consumers do not consume organic products because Spanish consumers have no appreciation against organic labels and tend to disrespect organic products.

\section{Method}

This study uses a fixed consumer of organic products incorporated as members of the Indonesian Organic Community. Data collected were 218 respondents. Data were collected incrementally through open surveys in the first phase and closed surveys using questionnaires in the second phase. The open question form conducted in the study includes basic motives to buy organic products such as evaluation of the benefits of organic products, anyone who participates in determining the purchase of organic products as well as a reference (reference) in buying organic products, factors that become barriers consumers to buy products organic. The first successful grouped power was then collected again using a closed questionnaire to describe the motives and barriers to purchasing organic products. Data collected through open surveys were then analyzed using FGD (focus group discussion) methods to classify aspects of motives and barriers. Content analysis techniques are used to analyze the collected data so as to find a group of prominent beliefs related to the behavior to be predicted. The results of the FGD were then compiled by the group of motives and barriers, and examined by experts or professional judgments, then collected data to be analyzed using CFA (Confirmatory Factor Analysis), and the data of motive and barriers organic products consumption are analyzed descriptively.

\section{Results}

The result of content analysis about the motives obtained from consumer product respondents indicates that the motives considered by consumers related to the consumption of organic products are health, safety, natural and the importance of maintaining environmental balance. External encouragement in the consumption of organic products is a life partner, family, friends or colleagues, while the reference is a medium of information such as magazines and television or talk shows and nutritionists. It is a barrier to the consumption of organic products is the availability of sellers (ease in obtaining organic products), product prices, consumer income, knowledge and information of authenticity (validity) of organic products. Schematically the interview results are grouped as follows:

Table 1. Categorization of Motives and Barriers on Organic Products Consumption

\begin{tabular}{llc}
\hline Variable & Response & Categorization \\
\hline Motives & Health & Internal \\
& Safety & \\
& Natural & \\
& Environmental balance & External \\
& Life partner & \\
Family & \\
& Friends or colleagues & \\
& Magazines & \\
& Television/Talk show & External \\
& Nutritionists & \\
\hline Barriers & Availability of sellers & Internal \\
& Price & \\
\hline
\end{tabular}

Sources: Primary data, 2018. 
The result of the rotation of the matrix component for each factor formed from the motive and the barriers stimulus of organic product consumption formed four factors with a factor loading value above 0.5 and a Kaiser-Meyer-Olkin value (KMO) of 0.747 greater than 0.500 indicating the adequacy of the amount sample in factor analysis. Confirmatory Factor Analysis results of the motives and barriers of organic products consumption as follows:

Table 2. Rotated Component Matrix

\begin{tabular}{|c|c|c|c|c|}
\hline \multirow{2}{*}{ Scales } & \multicolumn{4}{|c|}{ Component } \\
\hline & 1 & 2 & 3 & 4 \\
\hline Health & 887 & & & \\
\hline Safety &, 880 & & & \\
\hline Natural & ,865 & & & \\
\hline Environmental balance &, 856 & & & \\
\hline Life partner & &, 883 & & \\
\hline Family & &, 845 & & \\
\hline Friends or colleagues & & ,970 & & \\
\hline Magazines & &, 867 & & \\
\hline Television/Talk show & & ,914 & & \\
\hline Nutritionists & & ,846 & & \\
\hline Availability of sellers & & & & 843 \\
\hline Price & & & & 834 \\
\hline Information of authenticity (validity) & & & & ,784 \\
\hline Income & & & ,916 & \\
\hline Knowledge & & & ,840 & \\
\hline
\end{tabular}

Sources: Primary data, 2018.

Descriptive analysis is used in analyzing consumer motives related to the consumption of organic products and barriers faced by consumers in deciding the consumption of organic products. Based on the descriptive analysis, the consumer motive data to decide the consumption of organic products as follows:

Table 3. Percentage Motive of Organic Products Consumption

\begin{tabular}{lll}
\hline Motives & Categorization & Percentage \\
\hline Health & Internal & $84 \%$ \\
Safety & Internal & $67 \%$ \\
Natural & Internal & $39 \%$ \\
Environmental balance & Internal & $27 \%$ \\
Life partner & Eksternal & $52 \%$ \\
Family & Eksternal & $43 \%$ \\
Magazine & Eksternal & $39 \%$ \\
Nutritionist & Eksternal & $37 \%$ \\
Talk show/television & Eksternal & $34 \%$ \\
Friends or colleagues & Eksternal & $31 \%$ \\
\hline
\end{tabular}

Sources: Primary data, 2018. 
Health is the largest internal motive of consumers in buying organic products by $84 \%$. The next internal motive is a security issue of $67 \%$, natural at $39 \%$ and the lowest motive of consumers in buying organic products is maintaining an environmental balance of $27 \%$. The external motive for buying organic products was dominated by the pair, $52 \%$ followed by a family by $43 \%, 39 \%$ from magazines, nutritionists who made $37 \%$ decision models, $34 \%$ talk show and $31 \%$ colleagues' recommendation.

Based on the descriptive analysis, the barriers that faced by consumers to decide the consumption of organic products as follows:

Table 4. Percentage Barrier of Organic Products Consumption

\begin{tabular}{lll}
\hline Barriers & Categorization & Percentage \\
\hline Availability of the seller & External & $72 \%$ \\
Information of authenticity (validity) & External & $57 \%$ \\
Price & External & $43 \%$ \\
Income & Internal & $27 \%$ \\
Knowledge & Internal & $18 \%$ \\
\hline
\end{tabular}

Sources: Primary data, 2018.

The availability of the seller is the largest external barrier consumers have to decide on organic product consumption by $72 \%$. The next barrier is the presence of consumer concerns related to the authenticity (validity) of organic products by $57 \%$, consumers feel in doubt with the authenticity of the product. Price is the next barrier aspect of $43 \%$, organic products still seem expensive. Internally, consumer income is a barrier for consumers to decide on the consumption of organic products. Consumers also tend to admit to having no knowledge in distinguishing organic from non-organic. Aspects of knowledge also become a barrier to decide the consumption of organic products by $18 \%$.

\section{Discussion}

Based on the results of the analysis can be concluded that there are two groups of motive consumption of organic products namely internal and external motives. Internal motives include health, safety, naturalness, and the importance of maintaining environmental balance. External factors that determine the choice in the consumption of organic products is a spouse, family or relatives, friends or colleagues, while those used as a reference purchase is a medium of information such as magazines and television in the form of talk shows and nutritionists. Barriers that constrain the consumption of organic products in the form of external barriers (ease in obtaining products), product prices, information authenticity (validity) of organic products and internal barriers of income and consumer knowledge.

Consumers evaluate organic products based on the expected benefits of the consumption of organic products that stimulate consumers to buy organic products. Health is a key consideration for this consumer group. Consumption of organic products is part of a healthy lifestyle (Suprapto \& Wijaya, 2012) so that health orientation is the majority of consumer considerations. Health is categorized as a very important factor in buying organic products (Rana \& Paul, 2017) and has implications for buying intentions (Nedra et al., 2015). In addition to direct evaluation of organic products, consumers in deciding the consumption of organic products consider the reference model or reference norm that is the recommendation of spouses, family, nutritionists, colleagues and the media used as a reference such as magazines and television (talk show). The reference group is a consumer stimulus in deciding the consumption of organic products. The family is the most important consumer buying organization in the community and is the object of extensive research (Engel et al., 2000). Family members are the most influential primary reference group for purchases because they are closest to individuals, especially in Indonesia, which tend to be collective. The importance of the role of the family as influencers in the context of Indonesian consumers is evident in this study. References to aspects that are still rarely considered in the European context lead to differences in outcomes with this research. This is because the culture in Indonesia tends to be more collective which is different from the culture in the West which tend to be more individualistic. Indonesian society tends to pay attention to the importance of hope from people around crystallized in terms of consumption behavior.

Actual behavior is influenced by the influence of control factors (Ajzen, 2005), namely the influence of control factors that determine whether or not easy to behave. Consumers consider factors that facilitate or complicate 
consumers to consume organic products such as market availability, prices, aspects of consumer income / finance, and the existence of authenticity information (product legitimacy), unlike other countries such as Europe that have legalized the validity of organic products and widespread availability due to the high level of organic production supported by a good and equitable distribution system. The unavailability of organic products in traditional markets has caused consumers difficult access to organic produce (Barbarossa \& Pastore, 2015). Price is an aspect of the consumption of organic products in some countries, especially developing countries, which tend to have consumers who are sensitive to the price and supported by low consumer income. Sharma et al. (2016) also found a price to be a major barrier for consumers to decide on organic product purchases. Consumers need a guarantee or a validity indicator that the product consumed is a genuine organic product. This makes the control of consumer behavior in considering the consumption of organic products. The product's genuineness guarantee also reduces the level of risk consumers receive because consumers have no knowledge in identifying the authenticity of the product.

Regarding the internal motives of organic product consumption, organic producers in particular need to provide information in consumer education processes such as organic labeling and information such as the benefits of organic products for health. Kim et al., (2001) argues that a product label is a communication tool used to meet information and health needs. In general, information provided such as marks, content, ingredients, minerals, vitamins, logos for certain claims eg environmentally friendly, health claims, information suggestions and product use (Hingginson et al., 2002). Food labels are a useful way to help consumers make the right choice of products for health purposes (Worsley, 2002).

Consumer trust is a key prerequisite for establishing a market for credence goods, such as "green" products, especially when they are premium priced (Nuttavuthisit \& Thogersen, 2017). In addition, the food label can reduce the uncertainty faced by consumers (Zarkin \& Anderson, 1992), so as to reduce consumer doubt. The argument of using health claims is the most rational way to communicate product knowledge that can provide beneficial health effects to consumers (Oversen, 1999). Socialization of organic products from marketers is expected to increase consumer knowledge in overcoming the barriers of knowledge.

In terms of external motives, marketers need to approach family reference groups as part of marketing communications targets, family members are the most influential primary reference group in purchasing organic products. Although purchases are made by individuals, purchasing decisions are most likely to be influenced by other members of the family (Engel et al., 2005). Indonesian society as part of Asian culture, tend to collective so that individual decision is very influenced by reference group. In addition, producers of organic products can also use television and magazine media as a medium in educating consumers. The government or an independent institution needs to ensure the legality of the authenticity of organic products not only to the organic logo and to supervise the authenticity of the product. Thus, an organic certification body is needed to play a role in maintaining the legitimacy of organic products such as involving universities in organic certification efforts. Certification is the most important thing in Asia, this happens because of high consumer demand for assurance of certainty that the product to be purchased is genuine.

\section{Competing Interests Statement}

The authors declare that there are no competing or potential conflicts of interest.

\section{References}

Aertsens, J, Verbeke, W., \& Huylenbroeck, G, V. (2009). Personal determinants of organic food consumption: A review. British Food Journal, 111(10), 1140-1167. https://doi.org/10.1108/00070700910992961

Ajzen, I. (2005). Attitudes, personality, and behavior (2nd ed.). Berkshire, UK: Open University Press-McGraw Hill Education.

Aguirre, J.A. (2007). The farmer's market organic consumer of Costa Rica. British Food Journal, 109(2), 145-154. https://doi.org/10.1108/00070700710725509

Alberta Government. (2003). Organic consumer profile Canda: roping the web. Retrieved from www1.agric.gov.ab.ca.

Barbarossa, C., \& Pastore, A. (2015). Why environmentally conscious consumers do not purchase green product: A cognitive mind approach. Qualitative Market Research: An International Journal, 18(2). 188-209. https://doi.org/10.1108/QMR-06-2012-0030

Baudry, J., Peneau, S., Alles, B., Touvier, M., Hercberg, S., Galan, P., Amiot, M-J., Lairon, D., Mejean, C., \& Guyot, E, K. (2017). Food choice motives when purchasing in organic and conventional consumer clusters: 
Focus on sustainable concerns (The nutrinet-sante cohort study). Nutrients, 9(88), 1-17. https://doi.org/10.3390/nu9020088

Buder, F., Feldmann, C., \& Hamm, U. (2014). Why regular buyers of organic food still buy many conventional products. British Food Journal, 116(3), 390-404. https://doi.org/10.1108/BFJ-04-2012-0087

Calverley, C. (2005). Organic food market. ADAS, Wolverhampton.

Chan, R. Y. K. (2001). Determinants of chinese consumers green purchase behavior. Psychology \& Marketing, 18(4), 389-413. https://doi.org/10.1002/mar.1013

Chan, R. Y. K., \& Lau, L.B.Y. (2000). Antecedents of green purchases: A survey in china. Journal of Consumer Marketing, 17(4), 338-357. https://doi.org/10.1108/07363760010335358

Davies, A, Albert. J. T., \& Cochrane, C. (1995). Who buys organic food? A profile of the purchasers of organic food in Northern Ireland. British Food Journal, 97(10), 17-23. https://doi.org/10.1108/00070709510104303

Dembkowski, D, S., \& Lloyd, S, H. (1994). The environmental value attitude system model: a framework to guide the understanding of environmentally conscious consumer behaviour. Journal of Marketing Management, 10(7), 593-603. https://doi.org/10.1080/0267257X.1994.9964307

Doorn, J.V., \& Verhoef, P.C. (2015). Drivers and barriers to organic purchase behavior. Journal of Retailing, 9(3).436-450. https://doi.org/10.1016/j.jretai.2015.02.003

Engel, J. F., Roger, D. B., \& Paul, W. M. (2005). Consumer behavior. International Edition, Forth Worth: Dreyden Press.

Forman, J., \& Silverstein, J. (2012). Organic foods: Health and environmental advantages and disadvantages. Pediatrics, 130(5). e1406-e1415. https://doi.org/10.1542/peds.2012-2579.

Fraj, E., \& Martinez, E. (2006). Environmental values and lifestyles as determining factors of ecological consumer behaviour: An emprical analysis. Journal of Consumer Marketing, 23(3), 113-144. https://doi.org/10.1108/07363760610663295

Ham, M., Pap, A., \& Bilandzic, K. (2016). Perceived barriers for buying organic food products. Proceedings. 18th International Scientific Conference on Economic and Social Development "Building Resilent Society". Croatia 9-10 December.

International Federation of Organic Agriculture Movements. (2008). Retrieved from www.ifoam.org

Junaedi, S. (2007). The roles of consumer knowledge and emotion toward ecological issue: an empirical study of green study consumer behavior. International Journal of Business, 9(1), 81-99. https://doi.org/10.22146/gamaijb.5606

Kalafatis, S. P., Michael, R, E., \& Markos H. T. (1999). Green marketing and ajzen's theory of planned behavior: A cross-market examination. Journal of Consumer Marketing, 16(5), 441-460. https://doi.org/10.1108/07363769910289550

Laroche, M., Jasmin, B., \& Guido, B. F. (2001). Targeting consumers who are willing to pay more for environmentally friendly products. Journal of Consumer Marketing, 18(6), 503-520. https://doi.org/10.1108/EUM0000000006155

Lodorfos, G.N., \& Dennis, J. (2008). Consumers' intent: in the organic food market. Journal of Food Products Marketing, 14(2), 17-38. https://doi.org/10.1080/10454440801918218

Magistris, T., \& Gracia, A. (2008). The decision to buy organic food products in Southern Italy. British Food Journal, 10(9), 929-947. https://doi.org/10.1108/00070700810900620

Mie, A., Andesen, R, H., Gunnarsson, S., Kahl, J., Guyot-K, E., Rembialkowska, E., Quaglio, G., \& Grandjean, P. (2017). Human health implications of organic food and organic agricuture: a comprehensive review. Ennvirnmenal Health, 16(111), 1-22. https://doi.org/10.1186/s12940-017-0315-4

Nedra, B, A., Sharma, S., \& Dakhli, A. (2015). Perception and motivation to purchase organic products in Mediterranean countries: An empirical study in Tunisian context. Journal of Research in Marketing and Entrepreneurship, 17(1), 67-90. https://doi.org/10.1108/JRME-07-2014-0015

Nuttavuthisit, K., \& Thogersen, J. (2017). The importance of consumer trust for the emergence of a market for green products: The case of organic foods. Journal Business Ethics, 140(2), 140-337. https://doi.org/10.1007/s10551-015-2690-5 
Rana, J., \& Paul, J. (2017). Consumer behavior and purchase intention for organic food: A review and research agenda. Journal of Retailing and Consumer Services, 38(C), 157-165. https://doi.org/10.1016/j.jretconser.2017.06.004

Rembialkowska, E., \& Srednica, D. (2009). Organic food quality and impact on human health. Agronomy Research, 7(2), 719-727. http://agronomy.emu.ee/

Ruiz, F, T, J., Zamora, M, V., \& Rosa, M, P. (2018). False barriers in the purchase of organic foods: The case of extra virgin olive oil in Spain. Sustainability, 10(1), 1-14. https://doi.org/10.3390/su10020461

Sharma, P., Uprety, P., \& Phuyal, R, K (2016). An analysis of consumer's purchase behavior on organic foods in kathmandu valley. Advances in Economics and Business Management, 3(5), 514-526. Retrieved from http://www.krishisanskriti.org/Publication.html

Suprapto, B., \& Wijaya, T. (2012). Intention of indonesian consumers on buying organic food. International Journal of Trade, Economics and Finance, 3(2), 114-119. https://doi.org/10.7763/IJTEF.2012.V3.183

Tarkiainen, A., \& Sundqvist, S. (2005). Subjective norms, attitudes and intentions of Finnish consumers in buying organic food. British Food Journal, 107(11), 808-822. https://doi.org/10.1108/00070700510629760

Tsakiridou, E, Boutsouki, C, Zotos, Y., \& Mattas, K. (2005). Attitudes and behaviour towards organic products: an exploratory study. International Journal of Retail \& Distribution Management, 36(2), 158-175. https://doi.org/10.1108/09590550810853093

Wijaya, T. (2017). An Exploration Study of Values on Eco-Friendly Consumption in Indonesia. International Journal of Humanities \& Social Science Studies, $14(2), \quad 41-49$. https://doi.org/10.29032/IJHSSS.v4.i2.2017.41-49

\section{Copyrights}

Copyright for this article is retained by the author(s), with first publication rights granted to the journal.

This is an open-access article distributed under the terms and conditions of the Creative Commons Attribution license (http://creativecommons.org/licenses/by/4.0/). 